\title{
Performance of the High Solidity Wind Turbines in Low Wind Potential Sites of Sri Lanka
}

\author{
Mahinsasa Narayana ${ }^{1}$ and A G T Sugathapala ${ }^{2}$ \\ 1. National Engineering Research \& Development Centre of Sri Lanka \\ 2. University of Moratuwa
}

\begin{abstract}
Considering the wind potential in Sri Lanka, some sites have been identified as of low wind-potential. Grid-connected wind turbines have higher flexibility to be installed at good wind potential sites to obtain best performance. However, since off-grid wind turbines are used to provide power to fulfil the local energy requirement in the rural areas, they are not installed always at good wind-potential places but at sites in the vicinity of the energy requirement. Therefore, in certain instances, off-grid wind turbines must be designed to extract energy from low wind-potential sites to fulfil the energy requirement. The main objective of this study was to develop a suitable wind turbine generator (WTG) for low wind potential areas in Sri Lanka.
\end{abstract}

Keywords: wind turbine generator, wind speed, wind-rotor, blade-angles, chord-lengths, permanent magnet generator

\section{Introduction}

To improve the parformance of the rotor to extract more energy from low wind-speeds, it is necessary to reduce the cut-in wind speed and design wind speed of WTG. Low starting torque of wind rotors has been identified as the main restriction against the reduction of cut-in wind speed of WTGs. This study intends to analyse the aerodynamics of wind rotors theoretically and thereby introduce appropriate changes to the geometrical parameters of the blades. Especially, the possibility of increasing the solidity of the rotor, without adversely affecting its aerodynamic efficiency was analysed. The blade elementary theory and the momentum theory were used to analyse the aerodynamic performance of rotors theoretically. In this project a wind rotor was developed for an existing $100 \mathrm{~W}$ permanent magnet generator (PMG).

Manuscript received: 04.10.2004

Revised manuscript received: 18.02 .2005

Manuscript accepted: 23.02.2005

\section{Aerodynamic Performance of Wind Rotors}

The performance of the wind rotor is theoretically predicted by considering the wake-rotation of the wind-rotor by applying blade element theory and momentum theory, where the geometrical parameters $(\beta$ - blade angles, $l$ - chord lengths of each blade element) of the existing blade are used. The characteristic performance of a wind-rotor is usually given by the variation of power coefficient $\left(C_{p}\right)$ with respect to the tip-speed ratio $\left(\lambda_{0}\right)$.

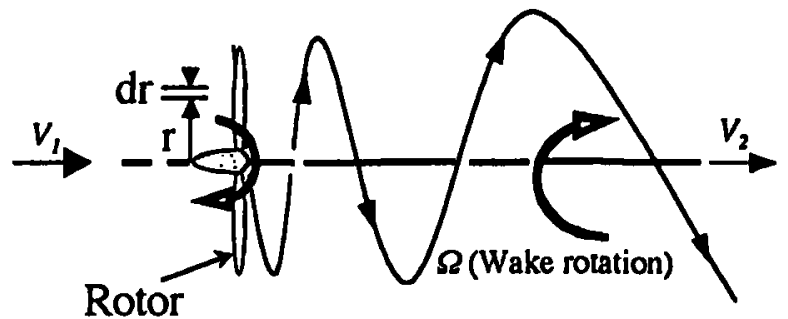

Figure 1: Flow behind the rotor with wake-rotational effect 
Downstream of the rotor (figure 1), the rotational speed of the wind flow is $\Omega$. Flow behind the rotor with wake-rotational effect is shown in Figure 1. Hence, $\Omega=h \omega$. Let, $V_{2}=k$ $V_{l}$. Where, $V_{l}$ - wind speed, $h$ - radial flow interference factor and $k$ - axial flow interference factor.

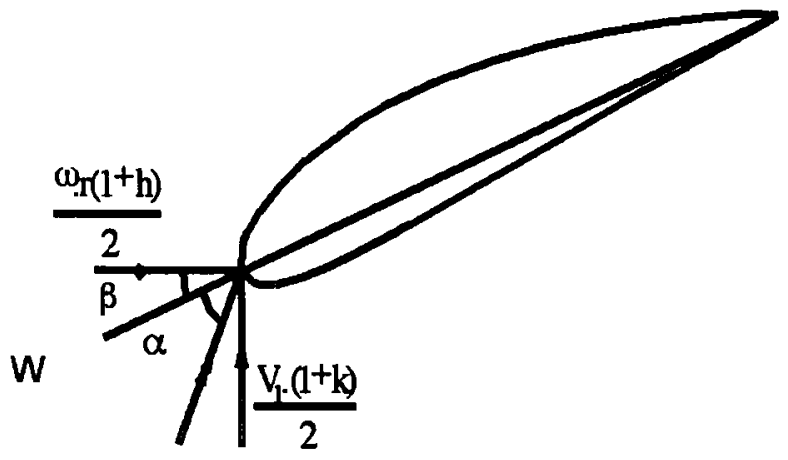

Figure 2: Velocity diagram of a blade element

Velocity diagram of a blade element is given in Figure 2. Considering the blade element theory, axial thrust $d F$ is given by:

$d F=b \cdot d \cdot F_{v}=\frac{1 / 2 \cdot \rho \cdot l \cdot W^{2} \cdot b \cdot C l \cdot \cos (\phi-\varepsilon) \cdot d r}{\cos \varepsilon}$

Aerodynamic torque, $d M$, is given by:

$d M=r \cdot b \cdot d F_{u}=\frac{1 / 2 \cdot \rho \cdot b \cdot l \cdot r \cdot W^{2} \cdot C l \cdot \sin (\phi-\varepsilon) \cdot d r}{\cos \varepsilon}$

where, $C_{l}$ - coefficient of lift, $C_{d}$ - coefficient of drag, $\tan \varepsilon=C_{d} / C_{l} \rho$ - air density, $b$ number of blades of wind rotor $\mathrm{W}$ - wind speed relative to the wind rotor, $l$ - chord length of blade element, incidence angle $(\phi)=\alpha+\beta$,

The above two values, $\mathrm{dF}$ and $\mathrm{dM}$, can be determined by the general dynamics theory. Consider the axial momentum of the flow through the annulus:

Thrust $=$ (rate of mass flow, $\mathrm{m}$, through the element) $x$ (change in the axial velocity).
Then, axial thrust,

$d F=\rho \cdot \pi \cdot r \cdot d r \cdot V_{l}^{2} \cdot\left(1-k^{2}\right)$

Aerodynamic torque,

$d M=\rho \cdot \pi \cdot r^{3} \cdot d r \cdot \omega \cdot V_{l} \cdot(1+k) \cdot(h-1)$

Comparing the expressions for axial thrust and aerodynamic torque derived by blade elementary theory with that derived by momentum consideration given in equations ${ }^{|3|}$.

$\frac{1-k}{1+k}=\frac{C l b l \cdot \cos (\phi-\varepsilon)}{8 \pi \cdot r \cdot \cos \varepsilon \cdot \sin ^{2} \phi}$

$\frac{h-1}{1+h}=\frac{C_{l} \cdot b \cdot l \cdot \sin (\phi-\varepsilon)}{4 \pi \cdot r \cdot \sin 2 \phi \cdot \cos \varepsilon}$

The wind rotor was divided into 10 equal sections and the $C_{p}$ value for each section was calculated by using the iterative procedure. The curve of coefficient of lift $\left(C_{i}\right)$ and of coefficient of drag $\left(C_{d}\right)$ verses the angle of attack $(\alpha)$ of the blade profile NACA 4415 was used for this calculation [1]. Then, coefficient of performance of the wind rotor segment at radius $\mathrm{r}\left(C_{p r}\right)$ with respect to different tip speed ratios $\left(\lambda_{0}\right)$ was calculated.

$C \mathrm{P}_{\mathrm{r}}=\frac{d P_{\mathrm{u}}}{\rho \cdot \pi \cdot r \cdot d r \cdot V^{3}}=\lambda^{2} \cdot(1+k) \cdot(h-1)$

Then, coefficient of performance of the wind rotor

$\left(C_{p}\right)$ is derived as follows.

$C_{p}=\frac{2}{R^{2}} \cdot \int_{r}^{R} C_{\mathrm{Pr} . r . d r}$

\section{Design of a Wind Rotor Suitable for Low Wind Potential}

Before discussing the design of a high solidity rotor it is important to study the starting torque 
of the wind rotor together with starting torque of the PMG. The initial torque of the PMG was measured at no load condition. The measured value is $0.34 \mathrm{Nm}^{|4|}$. When the PMG is coupled with the 12V-battery bank, it operates under no load condition until it generates $12 \mathrm{~V}$. Due to cogging effect of PMGs, it needs an initial torque to rotate even at the no-load condition. After performing many iterative calculations it has been found that the required rotor radius to generate the required starting torque at a specific solidity is $2.1 \mathrm{~m}$. The selected blade profile is NACA4415, and the selected number of blades is 4 . Chord lengths and other geometrical parameters of the wind rotor are given in Table 1. The optimum blade angle should be found for the selected chord length of each blade section, to obtain higher performance of the rotor. By applying the blade elementary theory and momentum theory, the following relations can be obtained.

$$
\begin{aligned}
& \frac{1-k}{1+k}=\frac{C_{1}(b . l / R) \cos (\phi-\varepsilon)}{8 \pi(r / R) \cos \varepsilon \sin ^{2} \phi} \\
& \frac{h-1}{1+h}=\frac{C_{1}(b . l / R) \sin (\phi-\varepsilon)}{4 \pi(r / R) \sin 2 \phi \cos \varepsilon}
\end{aligned}
$$

Table 1: Selected solidity of wind rotor to obtain the required higher torque coefficient $\left(C_{m}\right)$

\begin{tabular}{|l|l|}
\hline Radius (mm) & Chord (mm) \\
\hline 420 & 400.0 (Fixed) \\
\hline 630 & 378.8 \\
\hline 840 & 357.5 \\
\hline 1050 & 336.3 \\
\hline 1260 & 315.0 \\
\hline 1470 & 293.8 \\
\hline 1680 & 272.5 \\
\hline 1890 & 251.3 \\
\hline 2100 & 230.0 (Fixed) \\
\hline
\end{tabular}

At the optimum blade angle, $C / C_{d}$ should be minimum and optimum angle of attack $(\alpha)$ of the profile is known. If the number of Blades (b), Chord length $(l), C_{l} \varepsilon$ (tan $\varepsilon=C_{\gamma} C_{1}$ ), and speed-ratio $(\lambda)$ are known at a certain section of the rotor, $k$ and $h$ values of that particular section could be found for each angle $\phi$. At the optimum blade angle $\left(\alpha_{o p t}=5^{\circ}\right)$ of the NACA4415 profile, $C_{l}=0.95, C_{d}=0.008$, and $\varepsilon=8.42 \times 10^{-3} \mathrm{rad}$. Considering an element of rotor blade (Figure 2), the following expression can be derived:

$Y=\cot \phi-\lambda \frac{1+h}{1+k}$

Since $h$ and $k$ are functions of $\phi$, the above equation can be used to find the incidence angle $(\phi)$. However, even typical iterative methods do not give a convergent solution. Therefore a graphical method is used to find the solution. Here the graph of $Y=\cot \phi-\lambda \frac{1+h}{1+k}$ is plotted and the intercept of the graph is located. To get a uniform twist of the blade, blade angles should be linearised, by using the blade angle at the section of $0.4 \mathrm{R}$ and $0.9 \mathrm{R}$. Then, optimum incidence angles $\left(\phi_{\text {opp }}\right)$ are evaluated only at these sections. Solutions can be obtained by using Figure 3 and Figure 4. It has been noted that as the solidity of the rotor is increased the tip speed ratio should be decreased, to obtain a solution for $\phi$ at the optimum. (Otherwise there is no solution to Equation (9). In this design, solidity of the rotor is selected, while the blade-angle has been optimised. Suitable tip-speed ratio $\left(\lambda_{0}\right)$ of this optimisation is 3.5. Note that, conventional wind rotors are designed for obtaining high efficiency so that both solidity and blade angles are optimised. In the present design the rotor has a higher solidity, than that corresponding to optimum solidity for $\lambda_{0}=3.5$. Optimum incidence angles, blade angles and chord lengths at the section $r=0.4 R$ and $r=0.9 R$ of the designed wind rotor are presented in Table 2. 


$$
\cot \phi=\lambda \frac{1+h}{1+k} \text { Vs Angle } \phi
$$

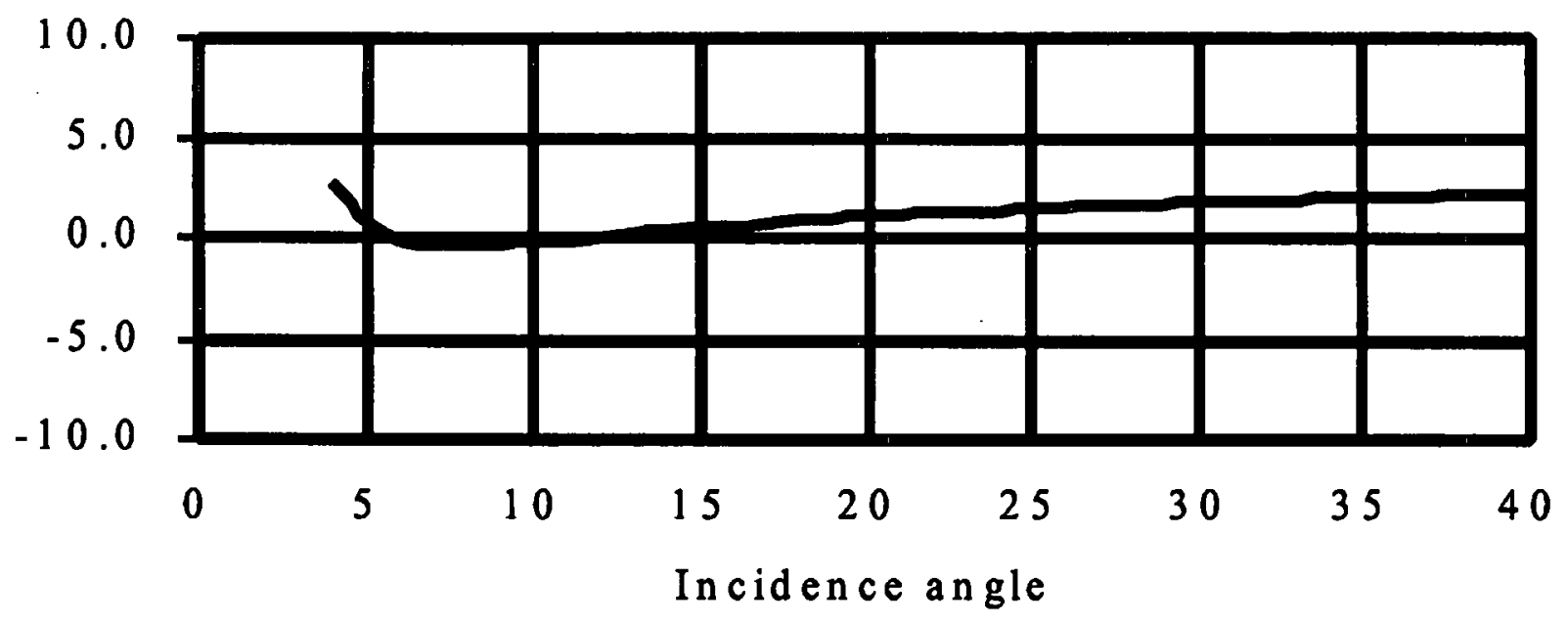

Figure 3: Optimum incidence $(\phi)$ angle at the section $r=0.9 R=1980 \mathrm{~mm}$

$$
\cot \phi-\lambda \frac{1+h}{1+k} \text { Vs Angle } \phi
$$

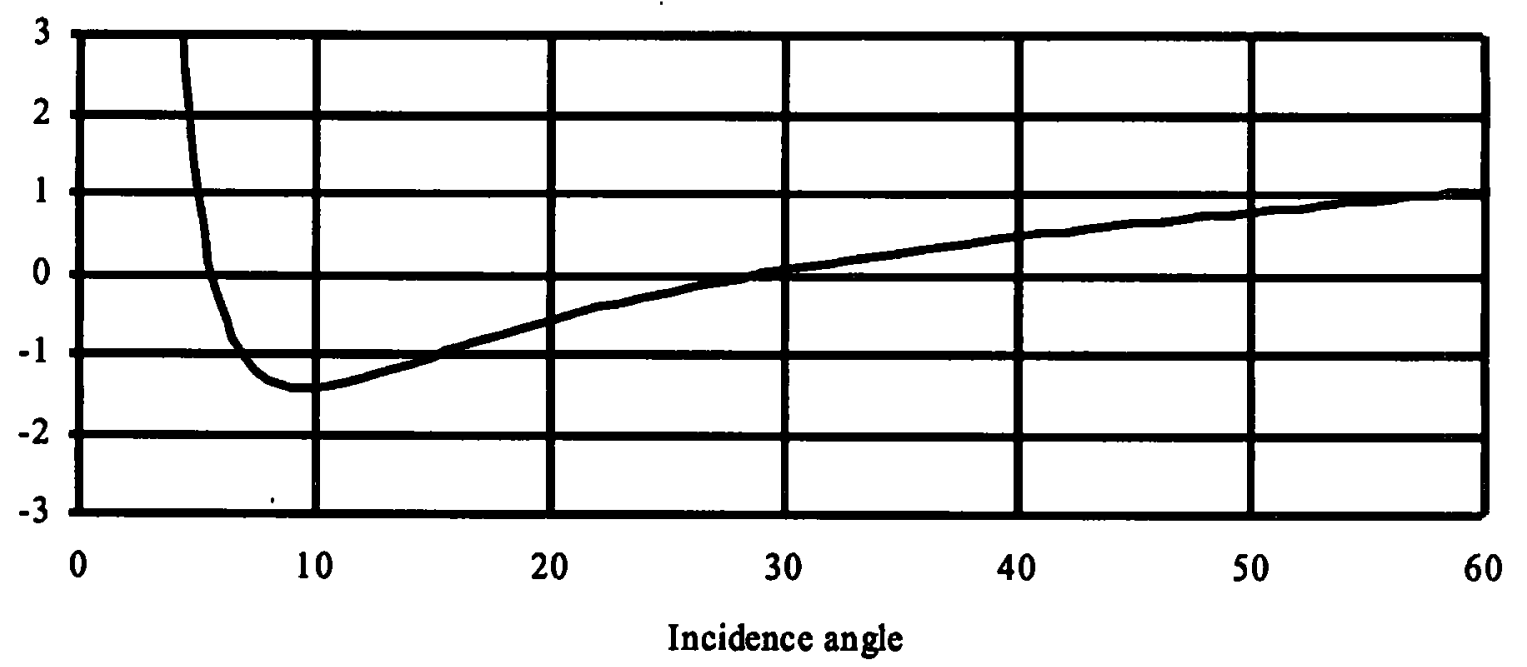

Figure 4: Optimum incidence $(\phi)$ angle at the section $r=0.4 R=880 \mathrm{~mm}$

Table 2: Optimum incidence angles ( $\phi_{\text {opt }}$ ), blade angles and chord lengths at the section $r=0.4 R$ and $r=0.9 R$ of the designed wind rotor

\begin{tabular}{|c|c|c|c|c|}
\hline Radius $(\mathrm{mm})$ & $\lambda,\left(\lambda_{0}=3.5\right)$ & Chord length $(\mathrm{mm})$ & Angle $\phi(\mathrm{Deg})$ & Angle $\beta(\mathrm{Deg})$ \\
\hline $0.9 \mathrm{R}=1890$ & 3.15 & 257.5 & 11.6 & 6.6 \\
\hline $0.4 \mathrm{R}=840$ & 1.4 & 351.3 & 27.2 & 22.2 \\
\hline
\end{tabular}


Table 3: Geometrical parameters of high solidity wind rotor

\begin{tabular}{|c|c|c|}
\hline $\begin{array}{c}\mathbf{R} \\
(\mathbf{m m})\end{array}$ & $\begin{array}{c}\text { Blade angle } \\
\beta(\mathbf{m m})\end{array}$ & $\begin{array}{c}\text { Chord, } \mathbf{~} \\
(\mathbf{m m})\end{array}$ \\
\hline 420 & 28.4 & 400.0 \\
\hline 630 & 25.3 & 378.8 \\
\hline 840 & 22.2 & 357.5 \\
\hline 1050 & 19.1 & 336.3 \\
\hline 1260 & 16.0 & 315.0 \\
\hline 1470 & 12.8 & 293.8 \\
\hline 1680 & 9.7 & 272.5 \\
\hline 1890 & 6.6 & 251.3 \\
\hline 2100 & 3.5 & 230.0 \\
\hline
\end{tabular}

\section{Performance of the High Solidity Wind Rotor}

The performance of the high solidity wind rotor is calculated theoretically by using the blade elementary theory and the momentum theory. Geometrical parameters of high solidity wind rotor with linerised blade angle and chord lengths are shown in Table 3. Wind rotor is divided into 10 sections and the $\mathrm{C}_{\mathrm{pr}}$ values are calculated for each section by using the searching procedure. Then $\mathrm{C}_{\mathrm{p}}$ and $\mathrm{C}_{\mathrm{m}} \mathrm{Vs} \lambda_{0}$ can be plotted for the rotor. The results are presented in Figure 6.

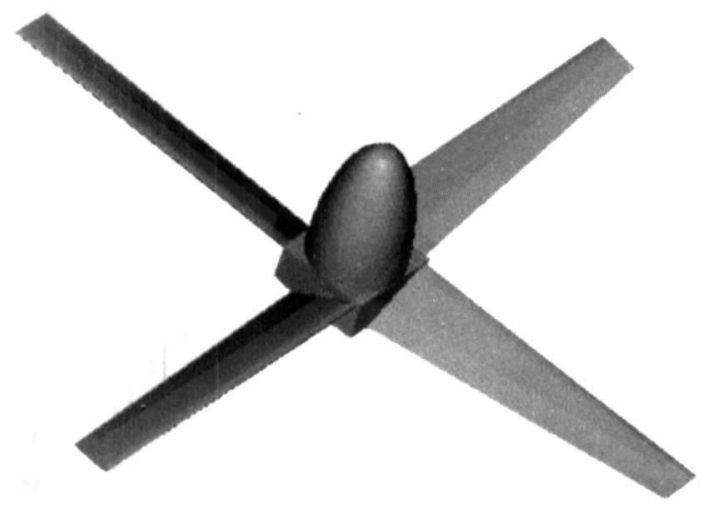

Figure 5: High-solidity 4-bladed wind rotor

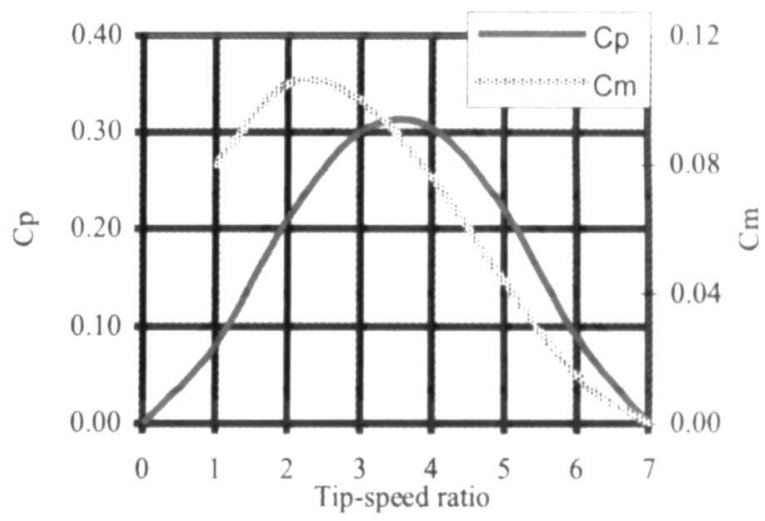

Figure 6: Power coefficient curve of 4-bladed high solidity

\section{System Performance of the Devel- oped high solidity Wind Turbine}

The combined characteristics of the WTG can be predicted based on the individual characteristics of the rotor and the PMG. These characteristics are presented together in Figure 7 , which shows the variation of power generated by the rotor at different wind speeds, and power output as a function of rotational speed. Note that the power input and outpat characteristics of PMG correspond to $12 \mathrm{~V}$ battery load. The speed increase ratio between the rotor and the generator for optimum performance should be approximately 1:5. The performance characteristics of WTG with the wind speed predicted through Figure 7 are presented in Figure 8. This indicates that cut-in wind speed of WTG is $2.5 \mathrm{~m} / \mathrm{s}$ and the rated wind speed is $5 \mathrm{~m} / \mathrm{s}$.

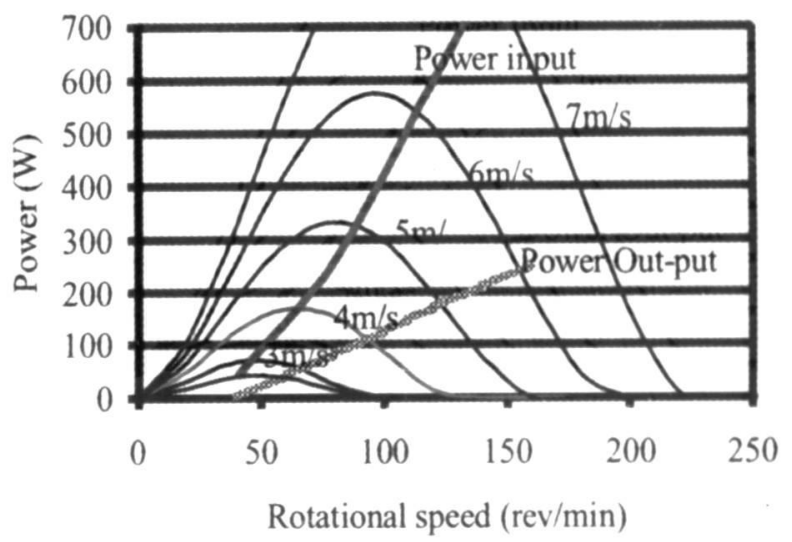

Figure 7: Combined performance of 4 bladed rotor and PMG (With 1:5 Gear Box) 


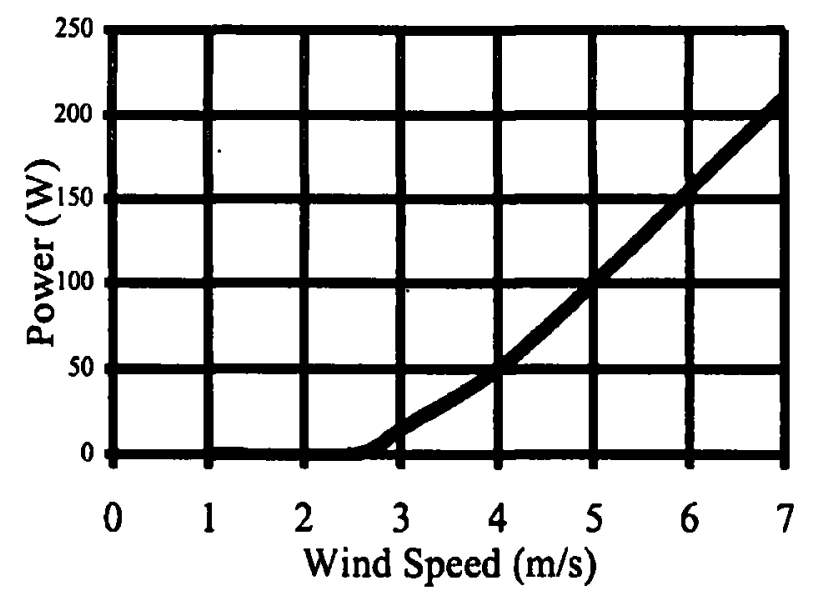

Figure 8: Performance of high-solidity 4-bladed WTG
As such, at low wind potential places in Sri Lanka the existing small-scale wind turbines could not fulfil the energy requirement for a rural house. However, it will perform well at good wind- potential places and will fulfil the energy requirement of a rural house in such an area.

\section{Performance of the Wind Turbine System at Different Sites}

\subsection{Design Wind Speed}

It is more appropriate to select the maximum energy content wind speed as the design wind

Table 4: The daily energy demand for a typical rural house in Sri Lanka

\begin{tabular}{|c|l|l|l|l|}
\hline No & \multicolumn{1}{|c|}{ Appliance } & Rated W & Daily use & Total (Wh/day) \\
\hline 1 & Compact fluorescent lamp (CFL) for kitchen & $11 \mathrm{~W}$ & $3 \mathrm{hr}$ & $33 \mathrm{Wh} /$ day \\
\hline 2 & Compact fluorescent lamp (CFL) for the living room & $11 \mathrm{~W}$ & $4 \mathrm{hr}$ & $44 \mathrm{Wh} /$ day \\
\hline 3 & $\begin{array}{l}\text { Compact fluorescent lamp (CFL) for out side the house or } \\
\text { one bedroom. }\end{array}$ & $11 \mathrm{~W}$ & $2 \mathrm{hr}$ & $22 \mathrm{Wh} /$ day \\
\hline 4 & Black \& white Television (12" screen) & $20 \mathrm{~W}$ & $3 \mathrm{hr}$ & $60 \mathrm{Wh} /$ day \\
\hline 5 & AM/FM radio stereo & $15 \mathrm{~W}$ & $7 \mathrm{hr}$ & $105 \mathrm{Wh} /$ day \\
\hline & Total Load & & & $264 \mathrm{Wh} /$ day \\
\hline
\end{tabular}

Table 5: Efficiency of electrical equipment used in wind power generation

\begin{tabular}{|l|l|}
\hline \multicolumn{1}{|c|}{ Equipment } & Efficiency \\
\hline DC to AC inverter & 85 to $95 \%$ \\
\hline $\begin{array}{l}\text { Battery charge regulator } \\
\text { (includes losses due to cables) }\end{array}$ & 90 to $95 \%$ \\
\hline Battery & 75 to $90 \%$ \\
\hline $\begin{array}{l}\text { Overall efficiency of the electrical } \\
\text { system }\end{array}$ & 57 to $81 \%$ \\
\hline
\end{tabular}

\section{Energy Requirement of a Rural Community}

The daily energy requirement for a typical house in Sri Lanka is presented in Table 4 and efficiency of electrical equipment used in wind power generation is shown in Table 5. Monthly energy requirement for a rural household in Sri Lanka is approximately $10 \mathrm{kWh}$. speed of the wind turbine than the wind speed with highest frequency of wind speed distribution. Therefore, the design wind speed of a given site could be determined by analysing energy frequency distribution of wind speeds. Based on this wind speed, rotor design can be carried out.

Therefore, the selection of design wind speed is a critical step in the wind system design process. The design wind speed is selected as the maximum energy content wind speed. This requires a detailed wind survey at the site. Further dependence on the demand and availability of energy requires different rotor designs. However, it is very difficult to design and manufacture different wind turbines suitable for each different site and a wind survey is not economical for small-scale wind power applications. Therefore, it may be more 
practical to design few categories of wind turbine systems and then the most suitable WTG can be selected according to the wind potential at the site. .

\subsection{Energy Indices of the Wind Turbine}

The energy potential of a given site can be represented by the following energy index:

Specific energy content of a site = Energy content per unit area at the site

There are different energy indices to represent the performance of a wind turbine system at a given site. These include,

Specific energy content per $\mathrm{kW}=\frac{\text { Net energy production }}{\text { Total installed power }}$

Capacity factor $=$

Net energy production

(Total installed power) $\times$ (Time duration)

Energy recovery factor $\left(C_{B}\right)=\frac{\text { Net energy production }}{\text { Total available wind power }}$

The net energy production is less than the gross energy production. The net energy is predicted by subtracting the losses from the gross energy. These losses occurr due to, climatology, wind turbulences, technical availability and dust on the blade. The total percentage of these losses is taken as $10 \%$ of the gross energy in the present study. In general, a good site should have a specific energy content of more than $83 \mathrm{kWh} / \mathrm{m} 2$ per month and a capacity factor of over $20 \%{ }^{[2]}$.

\section{Performance of the Wind Turbine at a Low Wind Potential Site}

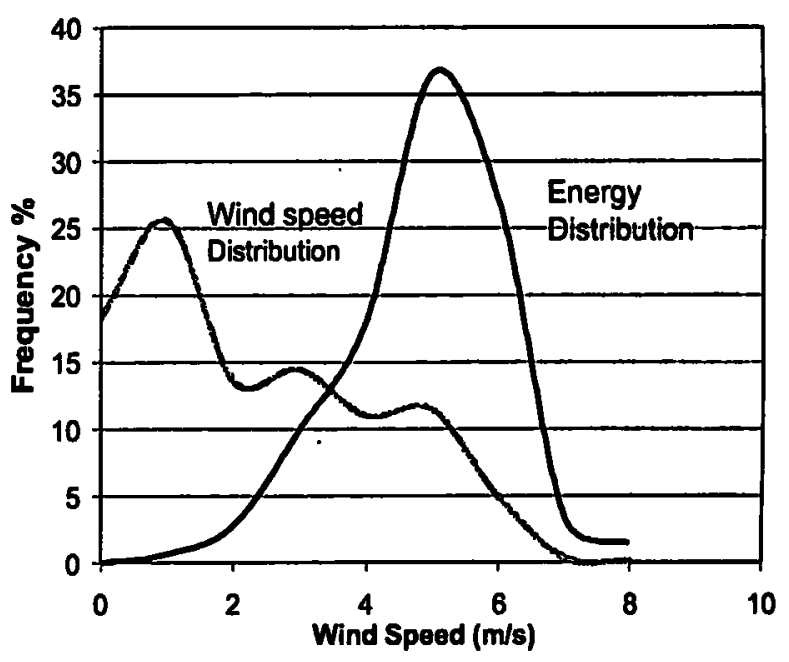

Figure 9: Wind speed and energy distribution at a rypical low wind speed site in Sri Lanka at $20 \mathrm{~m}$ heights

For comparison, NERDC design was used and an existing, small-scale wind turbine and wind resource at Ekala, in Sri Lanka, was taken as a typical low wind speed site. Wind speed and energy distribution in Ekala low wind speed site at $20 \mathrm{~m}$ heights is given in Figure 9. Power curve of NERDC Wind turbine generator is given in Figure 10. Total energy production of the NERDC design can be calculated on a monthly basis, by using the wind speed frequency distribution at Ekala site and the WTG performance characteristics.

Specific energy content of this site is $17.86 \mathrm{kWh} / \mathrm{m}^{2}$, and is less than the limit value of a good site of $83 \mathrm{kWh} / \mathrm{m}^{2}$. Capacity factor of this site is $6.43 \%$ and that is also less than the $20 \%$, which is the reference of a good site. Therefore, it could be concluded that this site is not a good wind potential site

Energy recovery factor $\left(C_{E}\right)$ of existing NERDC wind turbine is $6.98 \%$ at a low wind potential site, which is higher than that of the wind-turbine with a high-solidity rotor $\left(C_{E}=\right.$ $6.65 \%$ ). However, a high solidity wind turbine can produce $16.46 \mathrm{kWh}$ of energy per month 
while the existing NERDC wind turbine can produce $4.78 \mathrm{kWh}$ at a low wind potential site. Performance comparison of existing and designed wind turbines at a low wind potential site is given in Table 6.

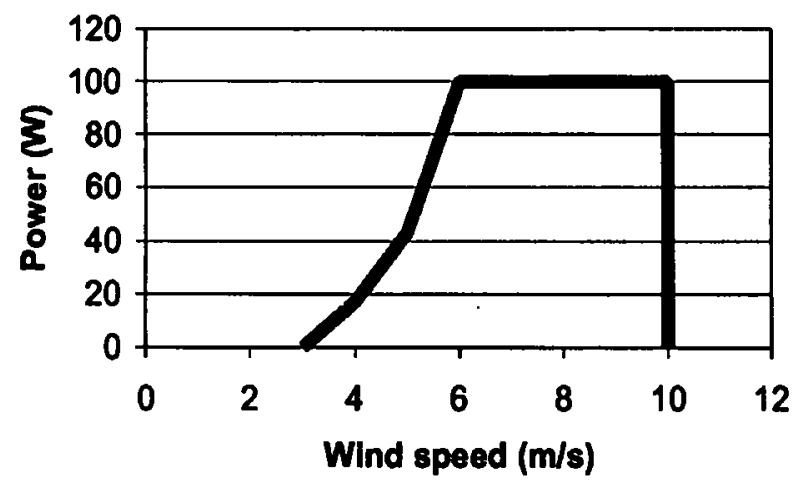

Figure 10: Power curve of NERDC Wind turbine generator ${ }^{11}$

Table 6: Performance comparison of existing and designed wind turbines at a low wind potential site

\begin{tabular}{|l|l|l|}
\hline \multicolumn{1}{|c|}{$\begin{array}{c}\text { Reference } \\
\text { parameters }\end{array}$} & \multicolumn{1}{|c|}{$\begin{array}{c}\text { Existing } \\
\text { wind } \\
\text { turbine }\end{array}$ [4] } & \multicolumn{1}{|c|}{$\begin{array}{c}\text { High } \\
\text { solidity } \\
\text { wind } \\
\text { turbine }\end{array}$} \\
\hline $\begin{array}{l}\text { Gross energy production / } \\
\text { month }\end{array}$ & $5.31 \mathrm{kWh}$ & $18.29 \mathrm{kWh}$ \\
\hline $\begin{array}{l}\text { Net energy production / } \\
\text { month }\end{array}$ & $4.78 \mathrm{kWh}$ & $16.46 \mathrm{kWh}$ \\
\hline $\begin{array}{l}\text { Specific energy content of } \\
\text { site }\end{array}$ & $\begin{array}{l}17.86 \\
\mathrm{kWh} / \mathrm{m}^{2}\end{array}$ & $\begin{array}{l}17.86 \\
\mathrm{kWh} / \mathrm{m}^{2}\end{array}$ \\
\hline $\begin{array}{l}\text { Specific energy content } \\
\text { per kW }\end{array}$ & $\begin{array}{l}48.6 \\
\mathrm{kWh} / \mathrm{kW}\end{array}$ & $\begin{array}{l}194.04 \\
\mathrm{kWh} / \mathrm{kW}\end{array}$ \\
\hline Capacity factor & $6.43 \%$ & $22.13 \%$ \\
\hline Energy recovery factor $\left(\mathrm{C}_{\mathrm{E}}\right)$ & $6.98 \%$ & $6.65 \%$ \\
\hline
\end{tabular}

Maximum overall-efficiency of the existing NERDC wind turbine is $12.8 \%$ and it is the highest overall-efficiency value compared with the high-solidity wind turbine. Maximum overall-efficiency of the wind turbine with a high-solidity rotor is $8.6 \%$. Graphical presentation of overall efficiencies of wind turbines is presented in Figure 11. The efficiency curve of the high-solidity wind turbine is shifted towards the low wind speeds range. Therefore, this wind turbine performs well at low wind speeds. When wind speed is less than $3.5 \mathrm{~m} / \mathrm{s}$, high solidity wind turbine gives the highest efficiency indicating its suitability for low wind potential sites.

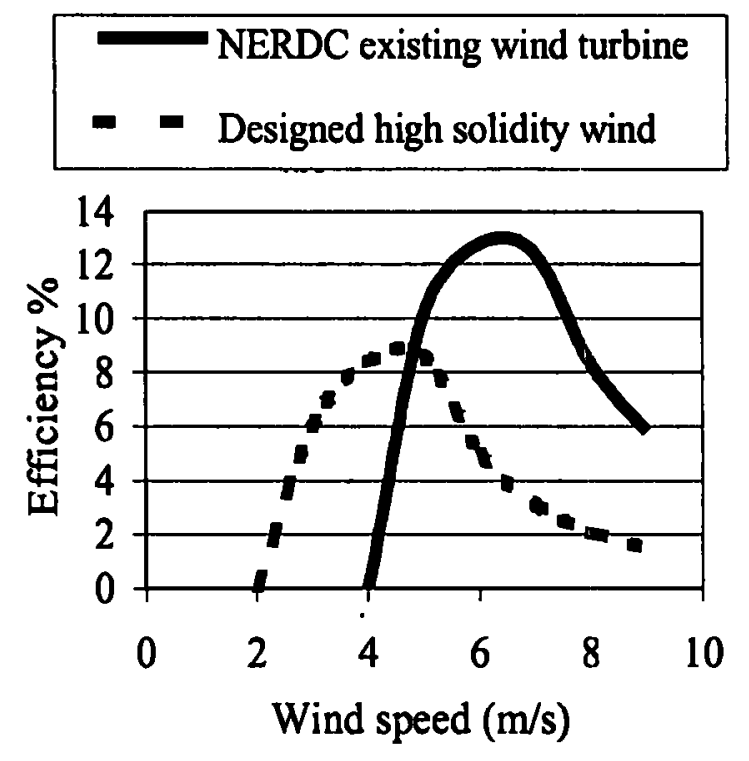

Figure 11: Overall efficiency of wind turbines

\section{Discussion}

This study has been carried out to design a new wind rotor which is suitable for low wind potential areas in Sri Lanka. A WTG for low wind-potential should be designed for low rated and cut-in wind speeds. When the rated wind speed is reduced, the diameter of the wind rotor should be increased in order to extract more energy from low wind-speeds. Low initial-torque of wind rotors is a main restriction against the reduction of the cut-in wind speed of WTG at low wind-speeds. Hence, solidity of the rotor should be increased to improve the starting torque, without affecting adversely its aerodynamic efficiency. In addition, in designing a WTG, the wind rotor and the generator should be properly matched for its optimum operation.

\section{References}

[1] Abbott. Ira. $\mathrm{H}$ and Von Doenhoff. Albert. E. Theory of Wing Section, pp412 and pp490-491, 1958. 
[2] Espace eolien developpement. "Renewable energy and efficiency capacity building, Wind assessment and project preparation", 16 rue Faidherbe-59000 LILLE, France, 1999.

[3] D. Le Gourieres Wind Power Plants Theory and Design. Oxford: Pergamon press, pp76-120, 1982.

[4] M Narayana, A G T Sugathapala, Performance of Battery-Charging Wind Turbine Developed by the NERD Centre, Tenth Asian Congress of Fluid Mechanics, University of Peradeniya, Sri Lanka, 17-21, May 2004.

\section{Biographical Sketches}

MAHINSASA NARAYANA, B.Sc. Eng. (Moratuwa), MPhil (Eng) (Moratuwa). Mr. Narayana is working in the NERD Centre of Sri Lanka as a Mechanical Engineer. and is specialized in the field of wind engineering and wind resource assessments.

A G T SUgathapala, B.Sc. (Hons.) (Moratuwa). PhD (Cambridge). Dr. Sugathapala is a Senior Lecturer in the Department of Mechanical Engineering, University of Moratuwa and lecturing in Fluid Dynamics, Wind Energy, Bio Energy and Mechanics of Materials for undergraduate and postgraduate students at the University of Moratuwa. 